J. Natn. Sci. Coun. Sri Lanka 198311 (\$): $269-275$

\title{
Nitrate-Nitrogen Content of Well Water and Soil from Selected Areas in the Jaffna Peninsula
}

\author{
RAJESWARY MAGESWARAN AND S. MAHALINGAM \\ Department of Chemistry, University of Jaffna, Jaffna, Sri Lanka. \\ (Date of receipt : 21 March 1983) \\ (Date of acceptance : 24 February 1984)
}

\begin{abstract}
This paper describes the results of a study concerning the amount of nitrate present in drinking water and soil in selected locations in the Jaffna Peninsula. In several places the ameunt of nitrate-nitrogen is above the safe level specified in the WHO International Standard for drinking water.
\end{abstract}

\section{Introduction}

In the Jaffna Peninsula there is a small acreage of Paddy lands but the majority of the cultivated lands is used for agricultural activity concerned with short term crops. Water for these is obtained from wells situated close by. Drinking water is also obtained from wells. In villages, each house or a group of houses has its own well. But in the Jaffna town and coastal areas like Kayts water is supplied by the Municipality and for this purpose the water is drawn from wells in the adjoining villages - Thirunelvely and Kondavil. These villages have a reasonable agricultural activity. Over the years it has been noted that Jaffna farmers have been using increasing quantities of fertilizers and attempts have been made to study the effect of large scale use of fertilizers on the ground water and soil. One of the serious problems is the increasing levels of nitrates and nitrites in drinking water which can be hazardous. Other sources of nitrates and nitrites are animal and human urine and excreta. It is also possible that some of the other nitrogen containing compounds are oxidised to nitrites and nitrates over the years.

It is well known that nitrates and nitrites above a certain level in drinking water and soil may caurse serious health problems due to their toxicity. It has been reported ${ }^{10}$ that if the drinking water contain more than $10 \mathrm{ppm}$ nitratenitrogen (45 ppm - nitrate), it could affect the health of infants and children. Apparently a microorganism in the gastrointestinal tract can convert nitrate into nitrite which under the biochemical conditions oxidises the $\mathrm{Fe}^{t \rightarrow}$ in haemoglobin to $\mathrm{Fe}^{+++}$, producing methaemoglobin. Methaemoglobin cannot transport oxygen in the blood and the resulting oxygen deficiency produces the characteristic bluish skin colour $8,9,10$. Therefore nitrates in the water consumed by infants may give rise to methaemoglobinaemia (blue babies). 
That methaemoglobinaemia is associated with high nitrate content in drinking water, was first discovered in 1945. Since that time about 2000 cases of blue babies have been reported from North America and Europe. ${ }^{8}$

Excess of nitrate in the drinking water could also affect older children and adults. The nitrates can be converted to the nitrites which in turn can produce nitrosamines by reaction with suitable amino compounds in the body. ${ }^{10}$ Nitrosamines are carcinogenic and hence a hazard to human health.

Increased nitrogen in the soil also may cause serious health problems because some plants such as carrots could store this excess nitrate and then reduce it partly to nitrite within itself. The nitrites could convert haemoglobin to methaemoglobin or produce nitrosamines and thus the carrots containing excess nitrate is a health hazard?

\section{Experimental Methods and Materials}

Several methods ${ }^{3}$ are available for the estimation of nitrates. One method is to determine the total oxidised nitrogen and then subtracting the colorimetrically estimated value for the nitrite! The alpha naphthylamine-pink colour method ${ }^{1}$ may be employed to determine the amount of nitrite colorimetrically. Reduction of nitrate and nitrite with hydrogen generated by either iron filings in sulphuric acid or Devardas alloy in alkaline solution has been employed to estimate total oxidised nitrogen. The reduction of nitrate to nitrite could be carried out by cadmium-copper reagent ${ }^{2}$ and $\propto$-naphthylamine-pink colour method could be used to determine the total oxidised nitrogen. (It should be noted that $\propto$ naphthylamine is carcinogenic). Another method uses 2:6 xylenol as indicator in a colorimetric determination of nitrates.

In our investigation, the nitrate-nitrogen was estimated by nitrophenoldisulphonic acid yellow colour method6. This method depends upon the nitration of position 6 of phenol-2,4-disulphonic acid.

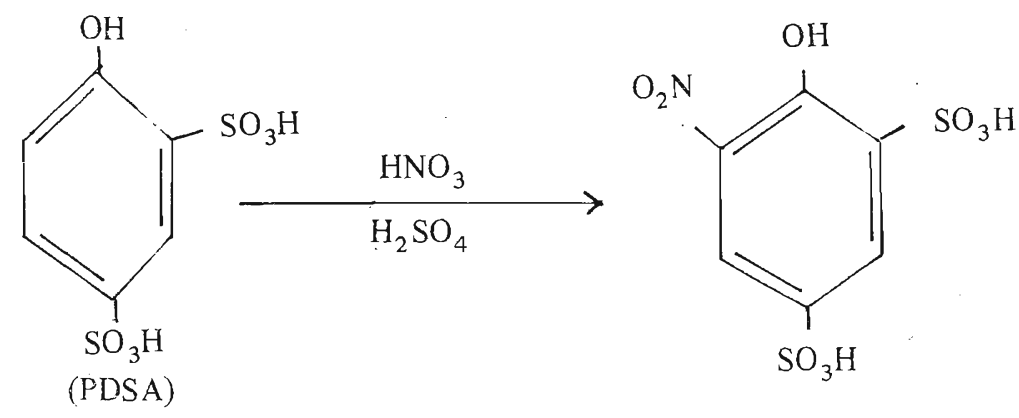


Phenol-2, 4-disulphonic acid was prepared ${ }^{6}$ by heating a mixture of phenol and conc $\mathrm{H}_{2} \mathrm{SO}_{4}$ in boiling water bath.
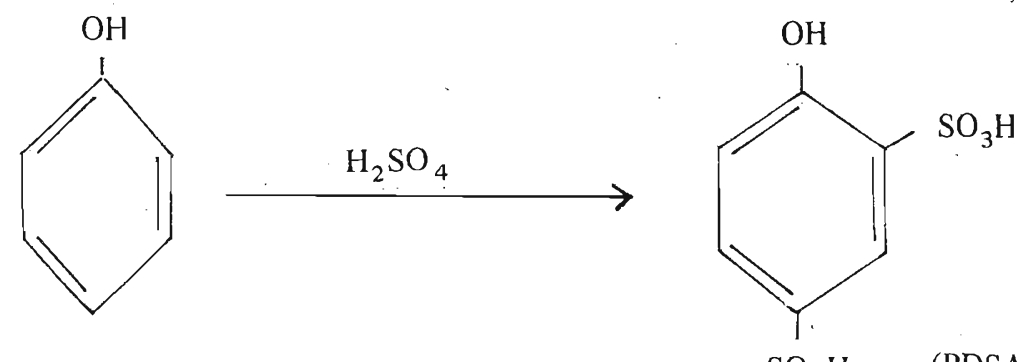

$\mathrm{SO}_{3} \mathrm{H}$

The amount of sodium, potassium and calcium in water samples were determined immediately after collection using a Corning Model 400 flame photometer. The flame intensities for sodium were corrected for interference by calcium by the standard - addition methods The samples were collected in clean dry dark glass bottles with bakelite screw caps and when necessary they were stored at $\mathrm{O}^{\circ} \mathrm{C}$. The nitrate-nitrogen was determined within three days of collection.

Two litres of water samples were concentrated and made up to $25 \mathrm{ml}$ with distilled water in a volumetric flask. These samples were used for colorimetric determinations.

The samples for colorimetric measurements were prepared as follows:

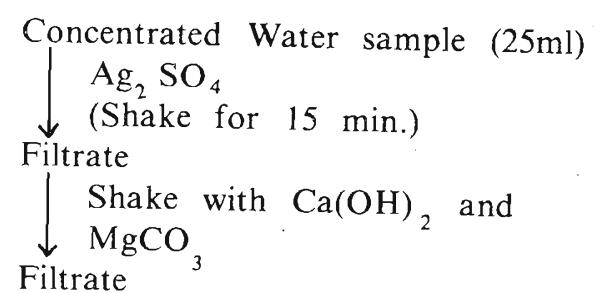

Filtrate

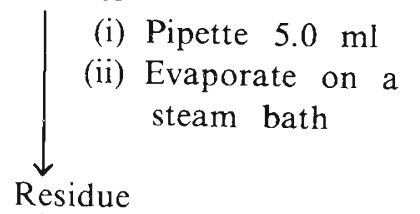

(i) Phenol-2, 4-disulphonic acid

(ii) Add $20 \mathrm{ml}$ water after $15 \mathrm{~min}$

Solution

$$
\downarrow \begin{aligned}
& \mathrm{NH}_{4} \mathrm{OH} \\
& \text { Alkaline solution (Yellow) } \\
& \text { (made to } 100 \mathrm{ml} \text { with distilled } \\
& \text { wate). }
\end{aligned}
$$

$$
\begin{gathered}
\text { Soil sample } \\
\text { Sieved } \\
22-\quad \begin{array}{c}
60 \text { mesh size } \\
0.2 \% \mathrm{CaSO}_{4} \\
\text { solution }
\end{array} \\
\begin{array}{c}
\text { Extract } \quad \text { Shake with } \\
\mathrm{Ag}_{2} \mathrm{SO}_{4}
\end{array} \\
\text { Filtrate }
\end{gathered}
$$

$\downarrow \begin{aligned} & \text { Shake with } \mathrm{Ca}(\mathrm{OH})_{2} \\ & \text { and } \mathrm{MgCO}_{3}\end{aligned}$

$$
\begin{aligned}
& \text { Filtrate } \\
& \text { (i) Pipette } 25.0 \mathrm{ml} \\
& \text { (ii) Evaporate on a } \\
& \text { Residue }
\end{aligned}
$$
(i) PDSA
(ii) add $20 \mathrm{ml}$ water after $15 \mathrm{~min}$.
Solution

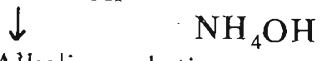

Alkaline solution

(Yellow) (made to $100 \mathrm{ml}$ ) 
The aqueous extract of the soil or water sample was evaporated to dryness previous to determination since the reaction must be effected in the virtual absence of water. The product behaves as a nitrophenolic type indicator - it is colourless in acid and yellow when neutralised or in alkaline solution. Ammonium hydroxide was therefore used to shift the $\mathrm{pH}$ to the yellow range for colorimetric determination.

The optical densities of test solutions were measured in a colorimeter (Corning 252) using a $420 \mathrm{~nm}$ filter and from the results obtained nitrate-N content was calculated using a reference graph.

Standard nitrate solution containing $10 \mu \mathrm{g}$ nitrate-nitrogen per $\mathrm{ml}$ was prepared according to known procedure $6.50,10.00,12.00,14.00,16.00,18.00$, $20.00,23.00,25.00$ and $30.00 \mathrm{ml}$ aliquots of this solution were taken and subjected to identical procedure ${ }^{9}$ as in the case of test samples and optical densities were measured.

\section{1 Nitrate in Soil}

\section{Results and Discussion}

The results (Table I) shows that in several areas in the Jaffna Peninsula the soil samples have nitrates above the safe level. In plots where there is no cultivation, the amount of nitrate in soil adjoining the well is below $20 \mathrm{ppm}$ in majority of cases. But in those plots where there is cultivation the soil adjoining the well seems to have fairly large quantity of nitrate, usually above $30 \mathrm{ppm}$. The results however are not conclusive.

\subsection{Nitrate in well water}

The water samples from wells in plots where there is no cultivation have relatively low nitrate-nitrogen levels. Thus the wells in the following localities where there is no cultivation have less than $18 \mathrm{ppm}$ of nitrate-nitrogen.

(i) Post Office and Hospital of the Jaffna Town

(ii) Kopay houses

(iii) Naranthanai

(iv) Karaveddy 

(v) Thavady
(vi) Vannarponnai
(vii) Kokuvil
(viii) Uduvil
(ix) Irupalai
(x) Nallur
(xi) Kadduvan
(xii) Tellippalai
(xiii) Mirusuvil.

The water samples from the wells in plots where there is agricultural activity have nitrate-nitrogen levels between 20 and $50 \mathrm{ppm}$. The villages of Kondavil and Urumpirai where there is intense agricultural activity have very high nitrate-nitrogen level (30-50 ppm). Even water samples from wells in plots in these villages where there is no cultivation have more than $20 \mathrm{ppm}$ of nitratenitrogen.

The water samples from the wells in Thirunelvely and Kondavil from which water is drawn for town supply have a high nitrate-nitrogen levels (26-33 ppm) which are about three times the safe level. Our investigations also indicate that the nitrate-nitrogen levels in the water of the wells used for town supply gradually increases year by year. Thus the nitrate-nitrogen level of Thirunelvely water supply well water increased from $15 \mathrm{ppm}$ in December 1976 to about 22 ppm in December 1980 and to about 27 ppm in May 1982 (Table II). Similarly the nitrate-nitrogen level in the water sample from the town water supply well from Kondavil increased from $22 \mathrm{ppm}$ in December 1976 to about $30 \mathrm{ppm}$ in December 1980 and to about $34 \mathrm{ppm}$ in May 1982.

It is apparent that the indiscriminate use of fertilizer is the chief reason for the rapidly increasing nitrate-nitrogen level in well water. We feel that the Jaffna farmers are using fertilizers far in excess of what is required. This conclusion is supported by the fact that the quantity of fertilizer sold in Jaffna is very large.

In certain parts of the Jaffna town area where there is no cultivation the nitrate-nitrogen level in well water approaches $20 \mathrm{ppm}$. This is probably due to inadequate sewerage disposal facilities. Also in thickly populated areas the wells are situated close to the soakage pits of the toilets and this may result in increased nitrate-nitrogen levels in well water. With increasing demand for houses, the local authorities are willing to reduce the minimum distance between the wells and septic tanks from $35 \mathrm{ft}$ to about $25 \mathrm{ft}$. This could cause serious health problems in a district like Jaffna where the limestone rock is fairly close to the earth surface and hence minimum soakage and absorption is possible. 
Table 1. Amount of Nitrate-Nitrogen in well water and soil and the amounts of Na, $\mathrm{K}$ and $\mathrm{Ca}$ in well water

Locality

Amount of Nitrate $\mathrm{N}$

in $\mathrm{ppm}$ in
In well water samples amount of

Soil* Well Water* $\mathrm{Na}+/ \mathrm{ppm}^{*} \mathrm{~K}+/ \mathrm{ppmCa}^{2}+/ \mathrm{ppm}$
Jaffna Town (
a) Post Office
b) Hospital
c) Station Road
d) Koddady East
e) Koddady West

2. Vannarpannai (not cultivated)

3. Nallur (not cultivated)

4. a) Kokuvil (not cultivated)

b) Kokuvil (cultivated)

5. a) Thavady (not cultivated)

b) Thavady (cultivated)

6. Thirunelvely area
a) Thirunelvely water supply well
b) Thirunelvely Agricultural research station
6. c) Farm School (cultivated)
d) Thirunelvely (cultivated)

$\begin{array}{lrrrrl} & 19.6 & 26.3 & 1242 & 5.7 & 30.1 \\ & 10.7 & 21.3 & - & - & - \\ \text { i) } & 22.3 & 22.1 & - & - & - \\ \text { ii) } & 24.1 & 24.8 & 506 & 4.5 & 40 \\ & 21.3 & 23.6 & 454 & 4.2 & 36.5\end{array}$

7. Kondavil area

i) $\quad 6.3 \quad 10.0$

ii) $\quad 6.90 \quad 13.4$

i) $\quad 8.1 \quad 14.6$

ii) $\quad 9.1 \quad 17.7$

i) $\quad 12.2 \quad 20.7$

ii) $\quad 13.1 \quad 22.0$

i) $\quad 11.3 \quad 18.9$

ii) $\quad 12.0 \quad 19.8$

i) $\quad 11.3 \quad 18.0$

ii) $\quad 12.8 \quad 20.3$

i) $\quad 3.0 \quad 12.0$

ii) $\quad 4.3 \quad 12.4$

$3.0 \quad 2.2$

$2.0 \quad 8.5$

$2.5 \quad 18.6$

$3.1 \quad 6.7$

$8.4 \quad 26.5$

$\begin{array}{rll}161 & 7.4 & 22.8 \\ 182 & 7.5 & 23.2 \\ 53 & 1.2 & 14 \\ 202 & 3.4 & 21 \\ - & - & - \\ 122 & 2.2 & 22 \\ 138 & 2.4 & 26 \\ 1242 & 5.7 & 30.1 \\ - & - & - \\ - & - & - \\ 506 & 4.5 & 40 \\ 454 & 4.2 & 36.5\end{array}$

a) Kondavil East Vanniasingam

Veethy (cultivated)

b) Kondavil water supply well (not cultivated)

8. Irupalai (not cultivated)

9. Urumpirai (cultivated areas)

$\begin{array}{rrrrrl}\text { i) } & 31.6 & 41.0 & 134 & 2.0 & 29 \\ \text { ii) } & 25.6 & 28.5 & 146 & 2.2 & 25.8 \\ \text { iii) } & 27.0 & 29.5 & - & - & - \\ \text { iv) } & 28.8 & 32.6 & - & - & - \\ \text { ed) } & 7.2 & 33.0 & 759 & 3.7 & 32 \\ & 5.0 & 6.0 & 851 & 4.0 & 40\end{array}$

a) Urumpirai East

(samples from different wells)

b) Urumpirai West

$\begin{array}{rcl}\text { i) } & 31.6 & 41.0 \\ \text { ii) } & 47.0 & 43.0 \\ \text { iii) } & 25.6 & 38.6 \\ \text { iv) } & 38.8 & 39.6 \\ \text { v) } & 35.0 & 44.4 \\ \text { vi) } & 39.2 & 45.0 \\ \text { vii) } & 53.8 & 48.0 \\ \text { viii) } & 21.3 & 45.6 \\ \text { i) } & 310 & 53 \\ \text { ii) } & 58.8 & 50\end{array}$

(contd.) 
Table 1 (contd.)

Locality
Amount of Nitrate $\mathrm{N}$ in ppm in
In well water samples amount of

Soil*Well Water* $\mathrm{Na}+/ \mathrm{ppm}^{*} \mathrm{~K}+/ \mathrm{ppmCa}^{2}+/ \mathrm{ppm}$

10. Kopay (not cultivated)

11. Uduvil (not cultivated)

12. Chankanai (not cultivated)

13. Naranthanai (not cultivated)

14. Chavakachcheri (Paddy cultivation)

15. Mirusuvil (not cultivated)

16. Tellipalai (not cultivated)

17. Erlalai (cultivated)

18. Kadduvan (not cultivated)

19. a) Karaveddy (not cultivated)

b) Karaveddy (cultivated)

20. Thampachetty

$\begin{array}{rrcrl}23.5 & 14.0 & 156 & 3.8 & 23 \\ 26.5 & 15.0 & - & - & - \\ 24.5 & 4.0 & 1702 & 7.8 & 38 \\ 38.3 & 14.2 & 3381 & 35.2 & 32 \\ 1.2 & 1.5 & 53 & 6.0 & 6.6 \\ 8.5 & 1.2 & 76 & 32.8 & 9.4 \\ 5.2 & 5.3 & 104 & 2.4 & 29 \\ 40.0 & 28.0 & 64.4 & 1.4 & 21 \\ 28.0 & 8.6 & 140 & 6.3 & 31.5 \\ 11.4 & 17.0 & 621 & 3.5 & 35.5 \\ 31.6 & 38.0 & 759 & 4.3 & 34.8 \\ 21.3 & 17.5 & 621 & 25.8 & 21\end{array}$

* Amount of Nitrate - Nitrogen in soil is expressed as $\mu \mathrm{g}$ of Nitrate - Nitrogen per $\mathrm{g}$ of soil where as that in well. water as $\mu \mathrm{g}$ of Nitrate - Nitrogen per $\mathrm{ml}$ of water. The sodium values given are values corrected for interference by calcium.

Table 2. Jaffna Municipality Water Supply

\begin{tabular}{|c|c|c|c|c|c|c|}
\hline & & December & 1976 & December 1980 & February 1982 & May 1982 \\
\hline i) & Thirunelvely water supply & $15^{*}$ & & 22 & 26.3 & 27.2 \\
\hline ii) & Kondavil water supply & $22^{*}$ & & 30 & 33 & 34 \\
\hline
\end{tabular}

* Report from water resources board - Jaffna.

\section{Conclusion}

The Nitrate-Nitrogen level in well water in the Jaffna Peninsula is well above the safe level of $.10 \mathrm{ppm}$ and is increasing year by year. The possible reason for this is the increase in the use of fertilizer.

\section{References :}

1. CROSBY T.N. (1967) Proc. Soc. Wat. Treat. Exam 16:51.

2. DEAN, F. M. (1972) Marine Chemistry Vol. 1. Marcel Dekker. Inc. New York 162-167. 3. FISHMAN, M.J., ERDMANN, D.E. \& STEENIHEIMER, R.R.: (1981) Analytical Chemistry
53: 182R.

4. HARTLEY, A.M., \& ASAI, R. (1963) Analytical Chemistry 35: 1207.

5. HOBART, H. WILLARD, LYNNE L. MERRITT. \& JOHN A. DEAN.: "Instrumental Methods of Analysis" Van Nostrand Reinhold Company, 342. 
6. JACKSON, M. L. : (1973) Soil Chemical Analysis, Prentice Hall, India Ltd., Delhi 197-201.

7. Magiswaran, R. \& Mahalingam, S.: (1982) Proc. Anr. Sess. Inst. Chem., Cey. 13.

8. REPORT by Prof. C. L. SENN. Project Engineer of Market Town Water Supply - Jaffna Project.

9. ROBERT, W. McGILVERY : (1975) Biochemical Concepts. W.B. Saunders Company, London 424.

10. WHO International Standard for drinking water 1971. 